\title{
Initial response of fish trophic niche to hydrological alteration in the upstream of Three Gorges Dam
}

\author{
Jianzhu Wang ${ }^{1}$, Lei $\mathrm{Li}^{1}$, Jun $\mathrm{Xu}{ }^{2}$ and Binhe $\mathrm{Gu}^{1,3^{*}}$
}

\begin{abstract}
Introduction: Damming is one of the dramatic impacts to river food webs due to habitat fragmentation and changes in the hydrological regimes. The world's largest dam, the Three Gorges Dam (TGD), has been constructed in the middle of Yangtze River since 2003. The objective of this study was to understand the effects of altered hydrological regime on the trophic structure of fish food web along the hydrological gradient in the TGD.

Methods: Fish samples were collected from an upstream, a midstream and a downstream site of the Yangtze River upstream of the TGD in May and September of 2004. Muscle tissue of each fish species was determined for stable isotopic compositions $\left(\delta^{13} \mathrm{C}\right.$ and $\delta^{15} \mathrm{~N}$ ) which were used to calculate isotope-based Bayesian community-wide trophic metrics.

Results: Stable isotope trophic niche analysis reveals reduced utilization of basal resource and trophic niche space at the midstream and downstream sites. By contrast, community trophic diversity and species redundancy were higher at the downstream than the upstream and midstream, likely as the result of reduced the spectrum of basal resources. These findings suggested that the negative impacts on the overall trophic niche space from reduced flow, increased water depth and stagnancy occurred only one year after the completion of the TGD.

Conclusions: Altered hydrological regimes posed multiple impacts to the aquatic food web. Reduced flow and increased water depth within TGD has posed initial effects to the fish community trophic structure. Further collections ana analysis of ecological data to compare the fish trophic structure revealed in this study are needed to assess the long-term impacts of TGD on fish community structure and resources utilization.
\end{abstract}

Keywords: Three Gorges Dam (TGD), Fish, $\delta^{13} \mathrm{C}, \delta^{15} \mathrm{~N}$, Trophic niche, Yangtze River

\section{Introduction}

River damming is a dramatic anthropogenic factor affecting freshwater environments (Dynesius \& Nilsson 1994; $\mathrm{Xu}$ et al. 2013). Damming leads to habitat fragmentation, changes in water depth, alter the rates, seasonal timing, and durations of flow. These changes may in turn affect the physical, chemical, and biological features of the river systems (Sternberg 2006; Dudgeon 2011). Numerous studies on the negative impacts of damming to the river ecosystem have been reported around the world although

\footnotetext{
*Correspondence: gubinhe@gmail.com

'Engineering Research Center of Eco-environment in Three Gorges Reservoir Region, Ministry of Education, China Three Gorges University, Yichang 443002, China

${ }^{3}$ Soil and Water Science Department, University of Florida, Gainesville, FL, USA Full list of author information is available at the end of the article
}

damming may provide other benefits to the human societies (Finer and Jenkins 2012; McClain 2013).

The construction of the Three Gorges Dam (TGD) at the middle of Yangtze River in south-central China would also have a series of environmental consequences (Wu et al. 2003; Fu et al. 2003; Xu et al. 2013). Since TGD started storing water in late 2003, the water depth increased by $66 \mathrm{~m}$. The formerly narrow channel with torrential water flow has been converted to extensive stagnant water similar to the limnetic zone of a large lake system as increases in the water depth, alternations of hydrology, and other physical, chemical, and biological characteristics of Three Gorges Reservoir (TGR) and the downstream (Liu and Cao 1992; Salazar 2000; Wu et al. 2003; Xu et al. 2013). 
The Yangtze River has high diversity for freshwater fish species (Xie 2003). The changes in the ecological environment have been reported to affect the fish community of TGR and the downstream waters (Fu et al. 2003; Xie 2003; Chen et al. 2009). Gao et al. (2010) reported the impacts of TGD to the fish community structure such as shift of fish species from lotic to lentic dominance. Chen et al. (2011) reported changes in fish assemblages following the completion of TGD. Other studies focused on the reproduction of major commercially important fish such as the major Chinese carp (Zhang et al. 2012; Hu et al. 2014) or endangered species (Chen et al. 2011; Zhang et al. 2014) while some studies focused on heavy metal accumulation (Cai et al. 2012; Yi and Zhang 2012) or conservation biology (Zhang et al. 2014; Ye et al. 2014). There is a severe lack of research work on trophic ecology of fish related to the TGD construction. Zhang et al. (2007) reported the suspended organic matter as the major sources of a planktivorous fish in Yangtze River. Wang et al. (2014) analyzed carbon sources for select invertebrates and fish at three river sites upstream of the TGD.

Stable isotope analysis has become a powerful tool for the study of aquatic food web (Kling et al. 1992; Vander Zanden 2001). Early stable isotope studies on fish community were focused on dietary sources, feeding relationships, and trophic levels (Cabana and Rasmussen 1996; Gu et al. 1996; Pinnegar and Polunin 2000). Recently, stable isotope data from aquatic consumers have been used to conduct trophic niche analysis (Bearhop et al. 2004; Newsome et al. 2012). Layman et al. (2007) proposed six community-wide trophic metrics based on fish assemblages. The six niche metrics are measures of the total extent of spacing and trophic redundancy within a $\delta^{13} \mathrm{C}$ and $\delta^{15} \mathrm{~N}$ bi-plot. This approach is considered as a more in-depth utility of stable isotope data for the analysis of consumer's trophic niche. Jackson et al. (2011) proposed a Bayesian framework to standardize the calculation of these trophic niche metrics, which has been applied to several studies of terrestrial (Perkins et al. 2014) and aquatic trophic niches (Jackson et al. 2011; Abrantes et al. 2014).

We analyzed the stable carbon $\left(\delta^{13} \mathrm{C}\right)$ and nitrogen $\left(\delta^{15} \mathrm{~N}\right)$ isotopic compositions of fish and invertebrates in three sites with different hydrological regimes located in the upstream of the TGD. Since damming of rivers is the most dramatic anthropogenic factor affecting freshwater environments (Dynesius and Nilsson 1994; Dudgeon, 2000; 2011), the construction of the TGD would also have severe environmental consequences (Park et al. 2003: Dudgeon 2011). The main objective of this study was to compare the stable isotope niches and the fish trophic positions of the fish collected in the three study sites of Yangtze River. Information from this study may assess the initial changes of hydrology and the resultant ecological changes which may affect fish community structure as the result of the
TGD construction. Findings may provide important insights of the changes in fish trophic structure and will be useful for wildlife conservation and fisheries management of the TGD and dammed rivers in the world.

\section{Methods}

\section{Description of study sites}

The Yangtze River is the largest river in China and the third longest river in the world, with a length of $6300 \mathrm{~km}$ and a drainage basin of $1,808,500 \mathrm{~km}^{2}$ (Fig. 1). Tremendous periodic flood events occur in the summer with a dry period during the winter and spring. The Three Gorges Dam (TGD), which is the world's largest dam, has been constructed in the middle Yangtze River in south-central China. As a result, the water depth upstream of the dam had increased by $66 \mathrm{~m}$ since the Three Gorges Reservoir (TGR) began storing water in late 2003. The formerly narrow channel characterized by torrential water flow has been converted to an extensive stagnant water body similar to the limnetic zone of a large lake system, with corresponding increases in the water depth, alternations of the flow rate, dissolved oxygen, light availability, and temperature in the TGR (Table 1).

\section{Sample collection and processing}

Detail methods for sample collection and processing can be found in Wang et al. (2014). Briefly, all samples were collected in two trips to the study sites in September 2004 and May 2005 which represent the wet and dry periods, respectively. The validity of this study is first based on the assumption that equally effective sampling effort was placed and resulted in similar probability of harvesting a fish species across sites. This is valid because of the same fishing tools and similar time spent on each site. The middle Yangtze River hosted a high range of fish species, and our collection only reflected a portion of the common species present in this region.

Epiphytic algae were collected from substrate surface and rinsed repeatedly in deionized water to remove sediment particles and detritus. Particulate organic matter (POM) was collected from several depths with a water bottle along five cross-transects at each site. In the laboratory, water was passed through coarse $(100 \mu \mathrm{m})$ sieves and then filtered onto precombusted Whatman GF/C $(1.2 \mu \mathrm{m})$ glass fiber filters.

The invertebrates collected included zooplankton, snails, the stream crab (Sinopotamon yangtsekiense), and the river shrimp (Macrobranchium nipponense). Zooplankton were obtained from vertical hauls of a 100- $\mu \mathrm{m}$ plankton net from each of the five transects at each station. The snails, stream crabs, and river shrimp were hand-collected or captured with fish traps. Shells and gut contents were removed, and the individuals were rinsed with distilled water.

A total of 27 species of fish consisting of three to four individuals of each species (Appendix 1) were collected 


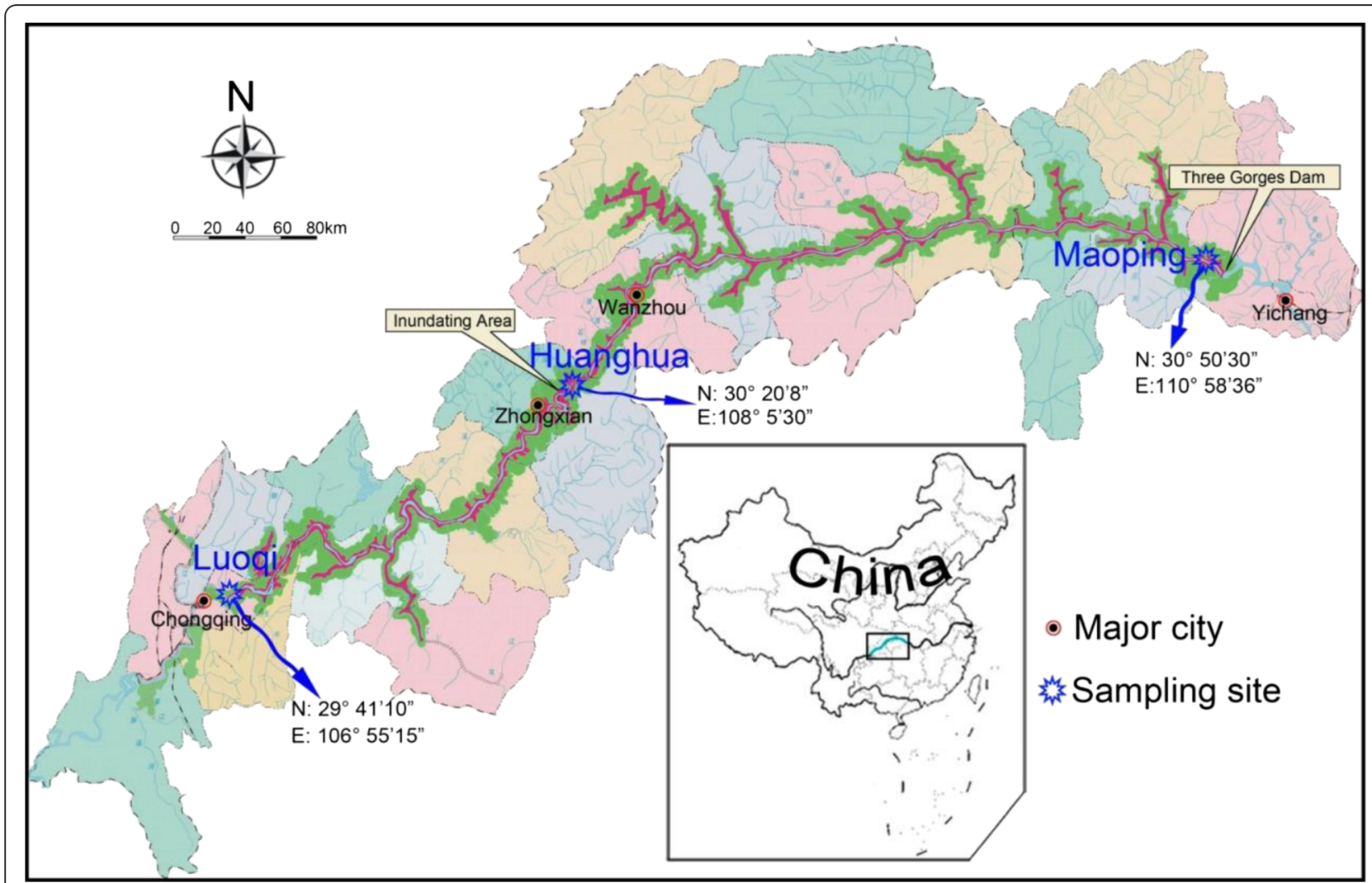

Fig. 1 Map of Three Gorges Reservoir area showing the three study sites and major cities

utilizing various fishing tools. For each fish captured, the total length was measured and recorded, and the dorsal white muscle tissue was removed and placed on ice in the field. In laboratory, all samples were dried at either $80^{\circ} \mathrm{C}$ for $24 \mathrm{~h}$ (plant organic matter) or $60{ }^{\circ} \mathrm{C}$ for $48 \mathrm{~h}$ (consumers) and ground into fine power using a mortar and pestle, or an agate mill for vascular plant samples. All equipment were washed with ethanol and dried between samples.

Table 1 Averages of selected environmental variables during the study period (2004-2005) at river sections near the three sampling sites along Yangtze River. Data are taken from Wang et al. (2014)

\begin{tabular}{|c|c|c|c|}
\hline Variable & Upstream & Midstream & Downstream \\
\hline Flow rate, $\mathrm{m} \mathrm{s}^{-1}$ & 1.75 & 0.36 & 0.17 \\
\hline $\mathrm{TP}, \mathrm{mg} \mathrm{L}^{-1}$ & 0.216 & 0.145 & 0.138 \\
\hline $\mathrm{TN}, \mathrm{mg} \mathrm{L}^{-1}$ & 1.665 & 1.494 & 1.357 \\
\hline $\mathrm{pH}$ & 7.36 & 7.9 & 8.2 \\
\hline $\mathrm{DO}, \mathrm{mg} \mathrm{L}^{-1}$ & 7.28 & 8.04 & 8.97 \\
\hline Conductivity, $\mu \mathrm{s} \mathrm{cm}{ }^{-1}$ & 248 & 372 & 279 \\
\hline $\mathrm{COD}, \mathrm{mg} \mathrm{L}^{-1}$ & 13.64 & 10.95 & 16.18 \\
\hline $\mathrm{Chl} \mathrm{a,} \mathrm{mg} \mathrm{m}^{-3}$ & 2.9 & 14.7 & 15.0 \\
\hline Number of fish species & 22 & 12 & 14 \\
\hline
\end{tabular}

\section{Stable isotope analysis}

The ${ }^{13} \mathrm{C} /{ }^{12} \mathrm{C}$ and ${ }^{15} \mathrm{~N} /{ }^{14} \mathrm{~N}$ ratios were determined using Thermo Finnigan MAT DELTA ${ }^{\text {plus }}$ XP isotope-ratio mass spectrometers at the Stable Isotope Laboratory for Ecological and Environmental Research at the Research Center for Plant Ecology, Beijing Institute of Botany, the Chinese Academy of Sciences. The isotope ratio is expressed in the conventional delta $(\delta)$ notation, defined as the per mil (\%) deviation from the isotope standard, Peedee Belemnite (PDB) formation and atmospheric $\mathrm{N}_{2}$ for ${ }^{13} \mathrm{C} /{ }^{12} \mathrm{C}$ and ${ }^{15} \mathrm{~N} /{ }^{14} \mathrm{~N}$, respectively. Routine precision for replicate samples was $\pm 0.1 \%$ for $\delta^{15} \mathrm{~N}$ and $\pm 0.3 \%$ for $\delta^{13} \mathrm{C}$.

\section{Estimate of stable isotope enrichments between fish and diets}

We investigated the diet compositions of yellow catfish (Pelteobagrus fulvidraco) and the Amur catfish (Silurus asotus) by gut content analysis. The food components were parted into terrestrial plants, plant debris, phytoplankton, benthic algae, zooplankton, shrimp, mollusk, and fish, and the proportion in bulk diet and their stable isotope values were measured for each of them (Table 2). The stable isotope values of bulk diets could be calculated as follow: 
Table 2 The dietary compositions of $P$. fulvidraco and C. heterodon revealed by gut content analysis and the stable isotope signatures

\begin{tabular}{|c|c|c|c|c|c|c|}
\hline \multirow[t]{2}{*}{ Food sources } & \multicolumn{3}{|c|}{ Diets of $P$. fulvldraco } & \multicolumn{3}{|c|}{ Diets of C. heterodon } \\
\hline & $\%$ & $\delta^{13} \mathrm{C}$ & $\delta^{15} \mathrm{~N}$ & $\%$ & $\delta^{13} \mathrm{C}$ & $\delta^{15} \mathrm{~N}$ \\
\hline Terrestrial plants & - & - & - & - & - & - \\
\hline Plant debris & - & - & - & 14.5 & -25.1 & 1.7 \\
\hline Phytoplankton & 8.5 & -23.8 & 5.3 & 23.0 & -23.2 & 4.2 \\
\hline Beneath algae & - & - & - & 8.5 & -22.9 & 10.3 \\
\hline Zooplankton & 27.0 & -22.9 & 6.7 & 21.5 & -23.7 & 6.2 \\
\hline Shrimp & 12.5 & -21.5 & 8.7 & - & - & - \\
\hline Mollusk & 32.5 & -22.1 & 7.4 & 27.5 & -22.6 & 6.9 \\
\hline Fish & 19.5 & -20.7 & 11.4 & 5.0 & -21.5 & 9.2 \\
\hline Bulk diet & & -22.1 & 8.2 & & -22.5 & 6.6 \\
\hline Discrimination $(\Delta)$ & & +0.47 & 3.3 & & -0.51 & 2.9 \\
\hline
\end{tabular}

"-" indicates that the food items were not found in the consumers' guts

$$
\delta^{15} \mathrm{~N}_{\text {bulk-diet }}=\sum f_{i} \times \delta^{15} N_{i}
$$

where $\delta^{15} \mathrm{~N}_{\text {bulk-diet }}$ were the stable isotope values of fish; the subscript $i$ represents one food source, $f$ represents the fractional contribution of each food source to fish diets, and $\delta^{15} \mathrm{~N}_{i}$ represents the stable isotope values for each food source. The isotope enrichment $\left(\Delta \delta^{15} \mathrm{~N}\right)$ between fish and their diets is calculated as follow:

$$
\Delta \delta^{15} \mathrm{~N}=\delta^{15} \mathrm{~N}_{\text {consumer }}-\delta^{15} \mathrm{~N}_{\text {bulk-diet }}
$$

There is a general agreement in that $\delta^{15} \mathrm{~N}$ increases by 2.8 to $3.8 \%$ per trophic level upward $\left(\Delta \delta^{15} \mathrm{~N}\right)$ in freshwater systems (Minagawa and Wada 1984; Post 2002). We calculated the isotope fractionation factor $\left(\Delta \delta^{15} \mathrm{~N}\right)$ from yellow catfish and the Amur catfish and their diets, and ${ }^{15} N$-enrichment per trophic level is about $3.1 \%$.

\section{Data analysis}

Site-specific stable isotope data from the two collection events were pooled prior to further data analysis. This is done because no significant differences in $\delta^{13} \mathrm{C}$ or $\delta^{15} \mathrm{~N}$ of fish between the two sample events for each site were found (ANOVA, all $p>0.05$ ). Trophic position $(\lambda)$ of each fish species was calculated with following equation (Post 2002):

$$
\lambda=\left(\delta^{15} \mathrm{~N}_{\text {consumer }}-\delta^{15} \mathrm{~N}_{\text {base }}\right) / \Delta \delta^{15} \mathrm{~N}+2
$$

where $\lambda$ is trophic position of a species of fish. $\delta^{15} \mathrm{~N}_{\text {consumer }}$ is the average $\delta^{15} \mathrm{~N}$ of the fish, $\delta^{15} \mathrm{~N}_{\text {base }}$ is the average $\delta^{15} \mathrm{~N}$ of the baseline organism. We used average $\delta^{15} \mathrm{~N}$ of grass carp (Ctenopharyngodon idellus) and Wuchang bream (Megalobrama amblycephala) which are true herbivores as the baseline. $\Delta \delta^{15} \mathrm{~N}$ is the isotope enrichment factor. The trophic level of the consumers used to estimate the baseline is 2 .

Six community-wide trophic metrics proposed by layman et al. (2007) were used to compare trophic niche between the study sites. The $\delta^{13} \mathrm{C}$ range $(\mathrm{CR})$ is the difference between the species with the most enriched and most depleted $\delta^{13} \mathrm{C}$ ratio and is a measure of basal resource diversity. The $\delta^{15} \mathrm{~N}$ range (NR) is the difference between the species with the most enriched and most depleted $\delta^{15} \mathrm{~N}$ ratio and is a measure of trophic length within a food chain. The total area (TA) of the $\delta^{13} \mathrm{C}$ and $\delta^{15} \mathrm{~N}$ bi-plot space (convex hull) describes the total space occupied by a community. The mean distance to the $\delta^{13} \mathrm{C}-\delta^{15} \mathrm{~N}$ centroid (CD) provides a measure of trophic diversity. The mean nearest neighbor distance (MNND) is the mean of the Euclidean distances to each species' nearest neighbor in bi-plot space and thus a measure of the overall density of species packing. Small MNND suggests increased trophic redundancy. Finally, the standard deviation of nearest neighbor distance (SDNND) is a measure of the evenness of species packing in bi-plot space. Low SDNND values mean more even distribution of trophic niches. $\delta^{13} \mathrm{C}$ vs. $\delta^{15} \mathrm{~N}$ biplots of each fish species in each site with standard ellipse areas (SEA) and convex hull (TA) were used to give the general figures for stable isotope distribution among sites. SEA was estimated using multivariate ellipse based metrics, which are bivariate equivalents to standard deviations in univariate analysis (Jackson et al. 2011). These analyses were performed using the $\mathrm{R}$ statistical computing packages ( $\mathrm{R}$ Development Core Team, 2007).

\section{Results}

Environmental variables and species composition of fish

Select hydrological, chemical, and biological variables from the three study sites are present in Table 1. The hydrological flow rate before the construction of the TGD was high across the study sites (Wang et al. 2014) but was greatly reduced after the completion of the dam to nearly stagnant at the downstream site. Nutrient (TP and TN) concentrations were high, indicating that all study sites were eutrophic, which is also supported by the moderately higher $\mathrm{pH}, \mathrm{DO}$, and COD and chlorophyll, a concentration in the midstream and downstream sites.

A total of 27 fish species were collected from the three study sites with species abundance highest at the upstream (22 species), moderate at downstream (14), and lowest at midstream (12). Chinese perch (Siniperca spp.) and largemouth bronze gudgeon (Coreius guichenoti) are on the national protected fish list which appear in all of the three study sites (Tables 3-5). However, ten species collected at the upstream site were not found at the midstream, and eight species were not found in the downstream sites and most of these fish are omnivores occupying the benthic habitat. The silver carp (Hypophthalmichthys molitrix) 
Table 3 Average, standard deviation (SD) of $\delta^{13} \mathrm{C}, \delta^{15} \mathrm{~N}$ ratios, and trophic level for all consumer taxa at the upstream site (Luogi) in Three Gorges Reservoir. Data were pooled from the wet and dry periods between 2004 and 2005

\begin{tabular}{lccc}
\hline Species & $\delta^{13} \mathrm{C}$ & $\delta^{15} \mathrm{~N}$ & Trophic level \\
\hline Ctenopharyngodon idellus & $-24.1 \pm 0.5$ & $5.5 \pm 0.3$ & $2.0 \pm 0.2$ \\
Megalobrama amblycephala & $-21.9 \pm 0.6$ & $8.7 \pm 0.3$ & $2.0 \pm 0.1$ \\
Cyprinus carpio & $-20.6 \pm 0.6$ & $7.2 \pm 05$ & $2.0 \pm 0.1$ \\
Carassius auratus & $-21.2 \pm 2.1$ & $8.1 \pm 0.6$ & $2.3 \pm 0.2$ \\
Coreius guichenoti & $-21.9 \pm 0.5$ & $8.6 \pm 0.6$ & $2.5 \pm 0.3$ \\
Hemibarbus maculatus & $-21.5 \pm 0.4$ & $9.5 \pm 0.5$ & $2.8 \pm 0.1$ \\
Pelteobagrus fulvidraco & $-21.6 \pm 0.8$ & $9.7 \pm .15$ & $2.8 \pm 0.4$ \\
Distoechodon tumirostris & $-21.1 \pm 0.4$ & $9.3 \pm 0.4$ & $2.7 \pm 0.2$ \\
Hemiculterella sauvagei & $-23.3 \pm 0.8$ & $8.4 \pm 0.4$ & $2.4 \pm 0.1$ \\
Abbottina guentheri & $-21.1 \pm 0.6$ & $8.3 \pm 0.3$ & $2.4 \pm 0.1$ \\
Hemimzon sinensis & $-22.3 \pm 0.3$ & $9.0 \pm 0.5$ & $2.6 \pm 0.1$ \\
Leptobotia elongate & $-21.9 \pm 0.7$ & $9.9 \pm 0.7$ & $2.9 \pm 0.4$ \\
Misgurnus anguillicaudatus & $-23.0 \pm 0.5$ & $9.3 \pm 0.7$ & $2.7 \pm 0.1$ \\
Schizothorax prenanti & $-22.6 \pm 0.5$ & $9.4 \pm 0.4$ & $2.7 \pm 0.2$ \\
Botia superciliaris & $-21.9 \pm 0.4$ & $10.9 \pm 0.4$ & $3.2 \pm 0.1$ \\
Gobiobotia Xenophysogobio & $-21.2 \pm 0.9$ & $8.9 \pm 0.5$ & $2.6 \pm 0.3$ \\
Saurogobio dabryi & $-22.6 \pm 0.5$ & $8.3 \pm 0.3$ & $3.0 \pm 0.1$ \\
Rhinogobio typus & $-12.0 \pm 0.1$ & $8.3 \pm 0.2$ & $2.4 \pm 0.1$ \\
Silurus asotus & $-21.1 \pm 0.9$ & $10.9 \pm 1.8$ & $3.2 \pm 0.5$ \\
Ophiocephalus argus & $-25.6 \pm 0.9$ & $10.3 \pm 0.7$ & $3.0 \pm 0.3$ \\
Siniperca chuatsi & $-24.0 \pm 0.8$ & $11.7 \pm 0.4$ & $3.5 \pm 0.2$ \\
Culter erythropterus & $-21.0 \pm 0.7$ & $11.9 \pm 0.4$ & $3.5 \pm 0.1$ \\
\hline
\end{tabular}

which is a planktivore living in the upper water column was collected at the midstream and downstream sites, but not at the upstream site. The longsout catfish (Leiocassis longirostris) and prenant's schizothoracin (Schizothorax prenanti) were collected from the downstream site only.

\section{Trophic level}

The diets of P. fulvldraco and S. asotus were identified and analyzed for stable isotope composition along with their muscle tissue. The trophic fractionation factor $\left(\Delta \delta^{15} \mathrm{~N}\right)$ from $P$. fulvldraco and S. asotus over their diets were 3.3 and $2.9 \%$, respectively, and the average (3.1\%) is used as the $\Delta \delta^{15} \mathrm{~N}$ for the estimates of trophic position for each species. Although the $\Delta \delta^{15} \mathrm{~N}$ values were based on the instant stomach content analysis and apparently did not consider seasonal variations in dietary composition, the average is similar to those reported previously (Post 2002).

The fish collected during this study may be classified into one of five general trophic guilds: herbivore, planktivore, omnivore, carninvore, and piscivore but were dominated by benthic omnivorous fish as other rivers. (Tables 3, 4, and 5). The trophic level of the fish assemblages
Table 4 Averages, standard deviation (SD) of $\delta^{13} \mathrm{C}$ and $\delta^{15} \mathrm{~N}$ ratios for all consumer taxa at the midstream site (Huanghua) in Three Gorges Reservoir. Data were pooled from the wet and dry periods between 2004 and 2005

\begin{tabular}{llrc}
\hline Species & \multicolumn{1}{l}{$\delta^{13} \mathrm{C}$} & \multicolumn{1}{c}{$\delta^{15} \mathrm{~N}$} & Trophic level \\
\hline Ctenopharyngodon idellus & $-23.3 \pm 0.4$ & $7.2 \pm 0.3$ & $2.0 \pm 0.1$ \\
Megalobrama amblycephala & $-23.3 \pm 0.3$ & $8.8 \pm 0.4$ & $2.0 \pm 0.1$ \\
Hypophthalmichthys molitrix & $-21.7 \pm 0.6$ & $7.7 \pm 0.3$ & $1.8 \pm 0.1$ \\
Cyprinus carpio & $-22.1 \pm 0.6$ & $8.1 \pm 0.6$ & $1.9 \pm 0.2$ \\
Carassius auratus & $-21.3 \pm 0.8$ & $10.4 \pm 0.4$ & $2.7 \pm 0.1$ \\
Coreius guichenoti & $-21.5 \pm 0.5$ & $9.5 \pm 0.3$ & $2.4 \pm 0.1$ \\
Hemibarbus maculatus & $-22.5 \pm 0.7$ & $9.8 \pm 0.3$ & $2.5 \pm 0.1$ \\
Pelteobagrus fulvidraco & $-21.2 \pm 1.2$ & $10.6 \pm 1.4$ & $2.8 \pm 0.4$ \\
Distoechodon tumirostris & $-22.0 \pm 0.2$ & $11.6 \pm 0.3$ & $3.1 \pm 0.2$ \\
Hemiculterella sauvagei & $-22.5 \pm 0.6$ & $9.1 \pm 0.3$ & $2.2 \pm 0.1$ \\
Silurus asotus & $-21.4 \pm 0.6$ & $12.7 \pm 0.9$ & $3.4 \pm 0.2$ \\
Siniperca chuatsi & $-23.5 \pm 0.9$ & $12.7 \pm 0.7$ & $3.4 \pm 0.2$ \\
\hline
\end{tabular}

at the three study sties ranged from 1.8 to 4.5 with an average of 2.7, 2.5, and 3.0 for the upstream, midstream, and downstream, respectively (Fig. 2). The grass carp and Chinese bream which appeared in all study sites were the only true herbivorous fish relying on large aquatic plants, and they are assigned as trophic level 2 fish. Silver carp which was only found in the midstream and downstream sites had a trophic level about 2 , indicating that they relied on primary producers. Most other fish were omnivores, typically positioned between trophic levels of 2 and 3.5. Species

Table 5 Averages, standard deviation (SD) of $\delta^{13} \mathrm{C}$ and $\delta^{15} \mathrm{~N}$ ratios for all consumer taxa at the upstream site (Maoping) in Three Gorges Reservoir. Data were pooled from the wet and dry periods between 2004 and 2005

\begin{tabular}{llcc}
\hline Species & \multicolumn{1}{l}{$\delta^{13} \mathrm{C}$} & \multicolumn{1}{l}{${ }^{15} \mathrm{~N}$} & Trophic level \\
\hline Ctenopharyngodon idellus & $-23.1 \pm 0.4$ & $8.0 \pm 0.4$ & $2.0 \pm 0.2$ \\
Megalobrama amblycephala & $-21.5 \pm 0.3$ & $6.6 \pm 0.4$ & $2.3 \pm 0.1$ \\
Hypophthalmichthys molitrix & $-22.8 \pm 0.6$ & $7.6 \pm 0.3$ & $2.1 \pm 0.1$ \\
Cyprinus carpio & $-21.9 \pm 0.3$ & $9.5 \pm 0.7$ & $2.7 \pm 0.2$ \\
Carassius auratus & $-22.8 \pm 1.1$ & $10.1 \pm 0.4$ & $2.9 \pm 0.2$ \\
Coreius guichenoti & $-22.9 \pm 0.4$ & $10.4 \pm 0.5$ & $3.0 \pm 0.1$ \\
Pelteobagrus fulvidraco & $-23.7 \pm 0.9$ & $13.0 \pm 1.1$ & $3.8 \pm 0.4$ \\
Hemiculterella sauvagei & $-21.4 \pm 0.6$ & $7.8 \pm 0.5$ & $2.2 \pm 0.1$ \\
Ophiocephalus argus & $-23.2 \pm 1.0$ & $12.5 \pm 0.5$ & $3.7 \pm 0.2$ \\
Schizothorax prenanti & $-23.4 \pm 0.6$ & $13.0 \pm 0.5$ & $3.8 \pm 0.1$ \\
Silurus asotus & $-22.2 \pm 1.0$ & $12.6 \pm 0.9$ & $3.7 \pm 0.2$ \\
Siniperca chuatsi & $-22.4 \pm 0.3$ & $13.5 \pm 0.5$ & $4.0 \pm 0.1$ \\
Culter erythropterus & $-22.0 \pm 0.4$ & $12.4 \pm 0.4$ & $3.6 \pm 0.1$ \\
Leiocassis longirostris & $-22.2 \pm 0.6$ & $13.0 \pm 0.5$ & $3.9 \pm 0.1$ \\
\hline
\end{tabular}



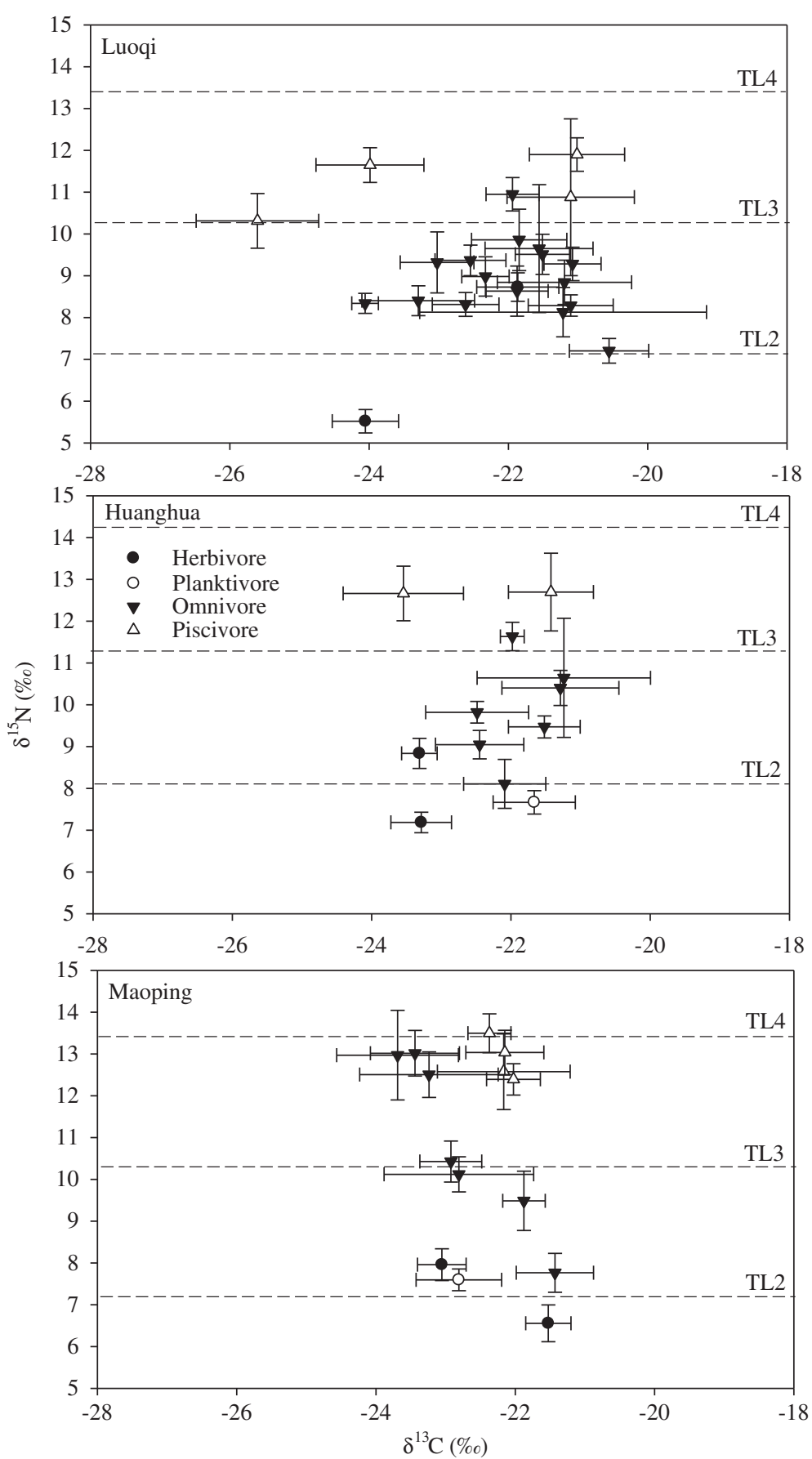

Fig. 2 Dual isotope plots of fish by trophic roles and trophic levels (TL) at the three study sites

which were collected from all study sites often tended to increase in trophic level from upstream to downstream. The high trophic level was especially apparent at the fish collected from the downstream site which were often 0.5 trophic level higher than the same species from the upstream site. Yellow catfish was a full trophic level higher than those from the upstream and midstream sites. However, the trophic level of Hemimzon sinensis at the downstream site was slightly lower than those form the other sites.

Food chain length defined as the highest trophic level of the fish from a habitat was 3.5 at the upstream, 3.4 at the midstream, and 4.0 at the downstream. Chinese perch was positioned at the highest TL at all study sites while the Redfin culter and the Amur catfish shared the same TL as the Chinese perch from the upstream and 
midstream site. The TL (3.9) of longsnout catfish which was only collected from the downstream site was slightly lower than the Chinese perch. Except for Amur catfish which preys on invertebrates and small fish, other three fish are largely piscivores.

\section{Trophic niche structure}

The Bayesian results of Layman trophic niche metrics were displayed in Fig. 3. The nitrogen range (NR) values were similar at upstream and downstream, but lower at the midstream. By contrast, carbon range (CR) was highest at the upstream and drastically reduced at the midstream and downstream sites. Similarly, the standard ellipse area (SEA) size was greatest at upstream and decreased considerably at midstream and downstream. The mean distance to the $\delta^{13} \mathrm{C}-\delta^{15} \mathrm{~N}$ centroid (CD) was nearly identical at both upstream and midstream and higher at downstream. Similar to CR and SEA, the mean nearest neighbor distance (MNND) and the standard deviation of nearest neighbor distance (SDNND) also displayed a trend of decreasing from upstream to downstream.

\section{Discussion}

Before the construction of the TGD, hydrology and fish assemblage at the three study sites was similar with high flow rates and fish diversity (Wang et al. 2014). A number of studies reported decreases in fish species after the completion of TGD (Gao et al. 2010; Liu et al. 2012). The alterations of physical (flow rate and pattern, and river stage) and biological habitat (dietary sources and abundance) are attributed to the changes in fish composition and abundance (Gao et al. 2010; Dudgeon 2011; Zhang et al. 2014). However, information on intrinsic trophic niche as a function of change of hydrological and biological regimes has not been reported. This study provided new and confirmative data for the illustration of the changes in fish ecology following hydrological alterations of dam construction.

Along with decreases in species diversity and appearance of the limnetic species, several major trophic niche metrics also pointed to the deterioration of the ecological niche at the downstream site since the completion of the TGD. Both $\delta^{15} \mathrm{~N}$ range (NR) and mean TL were greater at the downstream site than at the upstream site. Furthermore, the food chain length was also greatest at the downstream site with the Chinese perch occupying the highest trophic levels. The about 0.5 food chain length longer at the downstream than at other sites is likely attributed to more dietary organisms with higher trophic positions available at the more eutrophic downstream (Table 1).

The $\delta^{13} \mathrm{C}$ range (CR) is a measure of basal resource diversity. Compared to the midstream and downstream sites, the high $\mathrm{CR}$ at the upstream site reflected higher degree of resource diversity and the utilization of these resources by similarly high diversity of the fish assemblage.

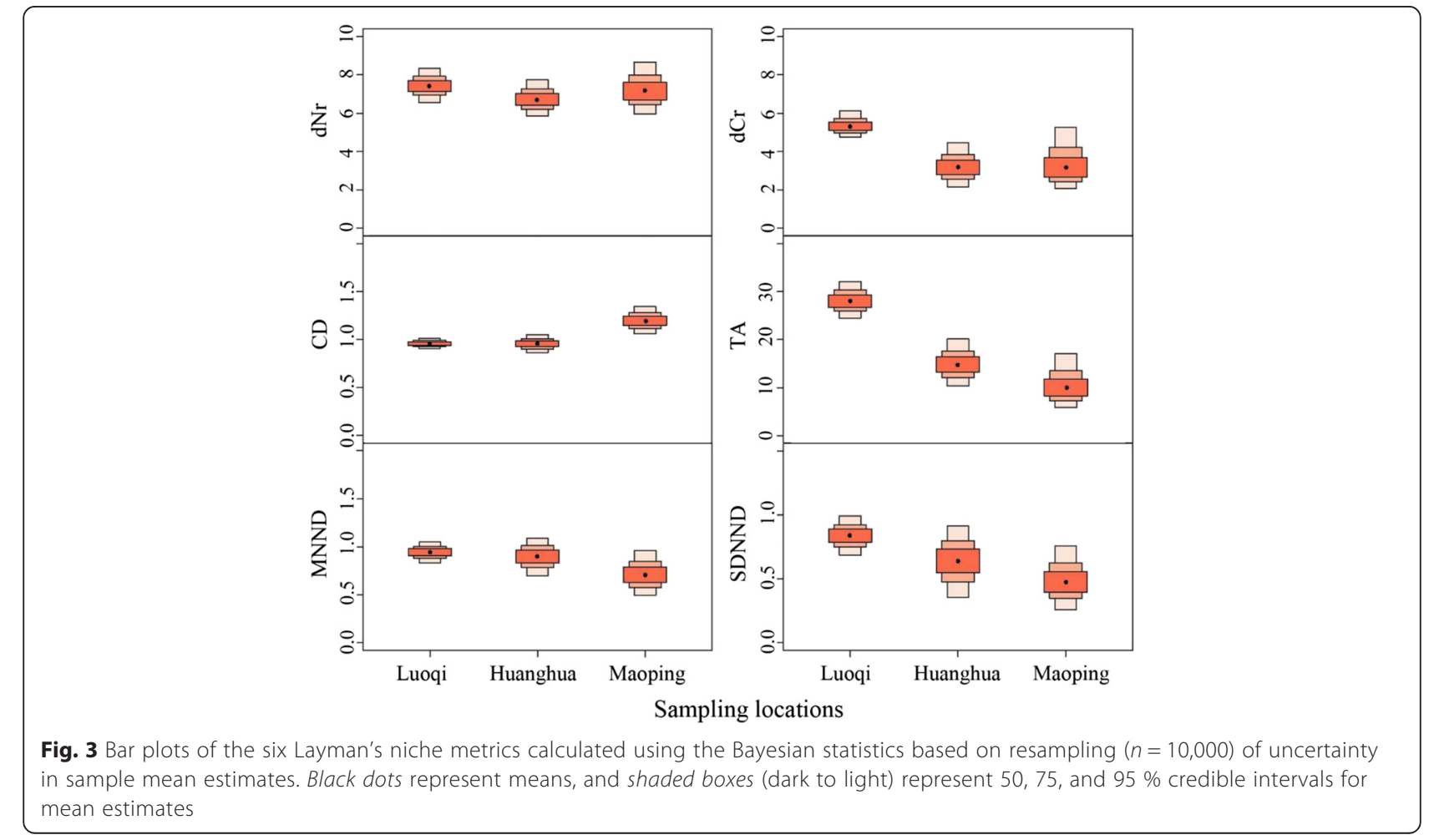


The low $\mathrm{CR}$ at the midstream and downstream sites where hydrological flow rates were also dramatically reduced may be attributed to the decreases in natural resources. This view is supported by the $\delta^{13} \mathrm{C}$ enrichment and depletion in common carp and snakehead collected at the upstream, respectively, which is over $1 \%$ and over $2 \%$ greater or less than those at the midstream and downstream. This might suggest a ${ }^{13} \mathrm{C}$ enriched and depleted basal resource, respectively, were absent at the lower reach of the river, likely as the result of decreasing availability of organic matter. The absence of snakehead with the most depleted $\delta^{13} \mathrm{C}$ at the midstream directly contributed to the small $\mathrm{CR}$ in this habitat. By contrast, Layman et al. (2007) showed that compared to pre-restored period, CR did not change because similar basal resources were present (Layman et al. 2005). Abrantes et al. (2014) also found trophic diversity in an African estuary increased as greater input of terrestrial organic matter during the wet period.

The niche space (SEA) is influenced by the end members of $\delta^{13} \mathrm{C}-\delta^{15} \mathrm{~N}$ for each consumer community. In this study, as discussed previously, the changes in SEA are mainly determined by CR which decreased considerably from upstream to downstream. The slight variation in NR from the upstream to downstream site does not affect the SEA as much as CR. Since the species which determined the trophic space basically appeared at all sites, we may conclude that it is resource availability which decreased along the river that affected fish trophic space of the community niche. This further supported findings from other measures in this study and other studies that alteration of hydrology impairs trophic niche in Yangtze and other lotic systems. The SEA is not affected by fish with intermediate $\delta^{13} \mathrm{C}-\delta^{15} \mathrm{~N}$ values so decreases in fish species diversity do not necessarily affect trophic space (Layman et al. 2007).

The mean distance to the $\delta^{13} \mathrm{C}-\delta^{15} \mathrm{~N}$ centroid (CD) provides a measure of average trophic diversity and is largely affected by the degree of species spacing (Layman et al. 2007). Although the trophic space (SEA) decreased from upstream to downstream, average trophic diversity (CD) increased from upstream to downstream, indicating that due to the absence of basal resources with extreme $\delta^{13} \mathrm{C}$ values, fish trophic spacing was more aggregated and fish shared more similar basal resources at the downstream. This is supported by the decreases in both NND and SDNND at the midstream and downstream sites where trophic distribution became more even and redundant within the reduced trophic space. Cooper and Wissel (2012) show that with species redundancy increased in more productive waters. Layman et al. (2007) but showed that NND and SDNND decreased as the result of similar trophic niches shared by new immigrant species post-restoration.

\section{Conclusions}

Our results on species abundance and composition and trophic niche characteristics pointed to the negative impacts of the construction of SGD on fish community structure and trophic spacing. This is done likely through reduced hydrological flow and increased water stagnancy which are unfavorable to fish adapted to lotic water before the dam construction. The slight increase in food chain length at the impacted or more productive site seems to be positive but severe loss of species diversity and trophic space also occurred. Our data were collected only 1 year after the completion of the TGD and can be viewed as the immediate impact, if any, by TGD. Data are being collected to assess the longer term effect of TGD on trophic niche and the contribution of basal resources to the fish assemblages at similar sites along the Middle Yangtze River.

Appendix 1 Name, common name, and trophic role for all fish taxa at the three study sites of the middle Yangtze River

\begin{tabular}{lll}
\hline Scientific name & Common name & $\begin{array}{l}\text { Trophic } \\
\text { role }\end{array}$ \\
\hline Ctenopharyngodon idellus & Grass carp & Herbivore \\
Megalobrama & Wuchang bream & Herbivore \\
amblycephala & & \\
Hypophthalmichthys molitrix & Silver carp & Planktivore \\
Cyprinus carpio & Common carp & Omnivore \\
Carassius auratus & Crucian carp & Omnivore \\
Coreius guichenoti & Largemouth bronze & Omnivore \\
& gudgeon & \\
Hemibarbus maculatus & Chinese minnow & Omnivore \\
Pelteobagrus fulvidraco & Yellowhead catfish & Omnivore \\
Distoechodon tumirostris & Round snout & Omnivore \\
Hemiculterella sauvagei & Spotted steed & Omnivore \\
Abbottina guentheri & Smallmouth gudgeon & Omnivore \\
Hemimzon sinensis & Chinese hillstream loach & Omnivore \\
Leptobotia elongate & Elongate loach & Omnivore \\
Misgurnus anguillicaudatus & Weather loach & Omnivore \\
Schizothorax prenanti & Prenant's schizothoracin & Omnivore \\
Botia superciliaris & Chinese sand loach & Omnivore \\
Xenophysogobio boulengeri & Ray finned carp & Omnivore \\
Saurogobio dabryi & Chinese lizard gudgeon & Omnivore \\
Rhinogobio typus & Longnose gudgeon & Omnivore \\
Silurus asotus & Amur catfish & Carnivore \\
Ophiocephalus argus & Snakehead & Carnivore \\
Siniperca chuatsi & Chinese perch & Piscivore \\
Culter erythropterus & Redfin culter & Piscivore \\
\hline & Leiocassis longirostris & \\
\hline
\end{tabular}




\section{Acknowledgements}

The authors are grateful to Leyi Li for his assistance in the stable isotopic measurements. The field and laboratory analyses were supported by two NSFCs (Grant Nos. 51179094 and 30700091) to J. Wang. Data analysis and manuscript preparation were supported by a NSFC (Grant No. 41376158) to B. Gu.

\section{Authors' contributions}

JW, the first author, achieved field work and laboratory analyses and provided the financial support for this study. LL prepared the samples for the measurement and organized the data. JX re-analyzed the data by $\mathrm{R}$ statistical computing packages. BG, the corresponding author, reorganized the data and prepared and modified the manuscript. All authors read and approved the final manuscript.

\section{Authors' information}

Jianzhu Wang, Ph. D./Associate professor/"151" backbone talents of China Three Gorges University (CTGU), graduated from Institute of Botany, the Chinese Academy of Science. His interests include stable isotopic ecology, restoration ecology, and pollution ecology. He had achieved two NSFCs as host and several national projects as a participator. He had published more than 20 papers in journals and achieved one first prize of provincial and ministerial level awards.

\section{Competing interests}

The authors declare that they have no competing interests.

\section{Author details}

${ }^{1}$ Engineering Research Center of Eco-environment in Three Gorges Reservoir Region, Ministry of Education, China Three Gorges University, Yichang 443002, China. ${ }^{2}$ Institute of Hydrobiology, the Chinese Academy of Sciences, Wuhan, China. ${ }^{3}$ Soil and Water Science Department, University of Florida, Gainesville, FL, USA.

Received: 13 March 2016 Accepted: 22 July 2016

Published online: 02 August 2016

\section{References}

Abrantes KG, Barnett A, Bouillon S (2014) Stable isotope-based community metrics as a tool to identify patterns in food web structure in east African estuaries. Funct Ecol 28:270-282

Bearhop S, Adams CE, Waldron S, Fuller RA, Macleod H (2004) Determining trophic niche width: a novel approach using stable isotope analysis. J Anim Ecol 73:1007-1012

Cabana G, Rasmussen J (1996) Comparison of aquatic food chains using nitrogen isotopes. Proc Natl Acad Sci 93:10844-10847

Cai S, Ni Z, Li Y, Shen Z, Xiong Z, Zhang Y, Zhou Y (2012) Metals in the tissues of two fish species from the rare and endemic fish nature reserve in the upper reaches of the Yangtze River, China. B Environ Contam Tox 6:922-927

Chen D, Xiong F, Wang K, Chang Y (2009) Status of research on Yangtze fish biology and fisheries. Environ Boil Fish 85:337-357

Chen S, Fath B, Chen B, Su M (2011) Evaluation of the changed properties of aquatic animals after dam construction using ecological network analysis. Procedia Environ Sci 5:114-119

Cooper RN, Wissel B (2012) Loss of trophic complexity in saline prairie lakes as indicated by stable-isotope based community-metrics. Aquat biosyst 8:6

Dudgeon D (2000) The ecology of tropical Asian rivers and streams in relation to biodiversity conservation. Annu Rev Ecol Syst 31:239-263

Dudgeon D (2011) Asian river fishes in the Anthropocene: threats and conservation challenges in an era of rapid environmental change. J Fish Boil 6:1487-1524

Dynesius M, Nilsson C (1994) Fragmentation and flow regulation of river systems in northern third of world. Science 226:753-762

Finer M, Jenkins CN (2012) Proliferation of hydroelectric dams in the Andean Amazon and implications for Andes-Amazon connectivity. Plos one 7(4):e35126

Fu CZ, Wu JH, Chen JK, Wu QH, Lei GC (2003) Freshwater fish biodiversity in the Yangtze River basin of China: patterns, threats and conservation. Biodivers Conserv 12:1649-1685

Gao X, Zeng Y, Wang J, Liu H (2010) Immediate impacts of the second impoundment on fish communities in the Three Gorges Reservoir. Environ Biol Fish 2:163-173
Gu B, Schelske CL, Hoyer MV (1996) Stable isotopes of carbon and nitrogen as indicators of diet and trophic structure of the fish community in a shallow hypereutrophic lake. J Fish Biol 49:1233-1243

Hu M, Hua Q, Zhou H, Wu Z, Wu X (2014) The effect of dams on the larval abundance and composition of four carp species in key river systems in China. Environ Biol Fish 98:1201-1205

Jackson AL, Inger R, Parnell AC, Bearhop S (2011) Comparing isotopic niche widths among and within communities: SIBER-Stable Isotope Bayesian Ellipses in R. J Anim Ecol 3:595-602

Kling GW, Fry B, O'Brien WJ (1992) Stable isotopes and planktonic trophic structure in arctic lakes. Ecology 73:561-566

Layman CA, Winemiller KO, Arrington DA, Jepsen DB (2005) Body size and trophic position in a diverse tropical food web. Ecology 86:2530-2535

Layman CA, Arrington DA, Montana CG, Post DM (2007) Can stable isotope ratios provide for community-wide measures of trophic structure? Ecology 1:42-48

Liu J, Cao W (1992) Fish resources of the Yangtze River basin and the tactics for their conservation. Resources and Environment in the Yangtze Basin 1:17-23

Liu F, Wang J, Cao W (2012) Long-term changes in fish assemblage following the impoundments of the Three Gorges Reservoir in Hejiang, a protected reach of the upper Yangtze River. Knowl Manag Aquat Ec 407:06

McClain ME (2013) Balancing water resources development and environmental sustainability in Africa: a review of recent research findings and applications. Ambio 42:549-565

Minagawa M, Wada $E$ (1984) Stepwise enrichment of $\delta^{15} \mathrm{~N}$ along food chains: further evidence and the relation between $\delta^{15} \mathrm{~N}$ and animal age. Geochim Cosmochim Ac 48:1135-1140

Newsome SD, Yeakel JD, Wheatley PV, Tinker MT (2012) Tools for quantifying isotopic niche space and dietary variation at the individual and population level. J Mammal 93:329-341

Park Y, Chang J, Lek S, Cao W, Brosse S (2003) Conservation strategies for endemic fish species threatened by the Three Gorges Dam. Conserv Biol 17:1748-1758

Perkins MJ, McDonald RA, van Veen FF, Kelly SD, Rees G, Bearhop S (2014) Application of nitrogen and carbon stable isotopes $\left(\delta^{15} \mathrm{~N}\right.$ and $\left.\delta^{13} \mathrm{C}\right)$ to quantify food chain length and trophic structure. PLoS One 3, e93281

Pinnegar JK, Polunin NVC (2000) Contributions of stable-isotope data to elucidating food webs of Mediterranean rocky littoral fishes. Oecologia 122:399-409

Post DM (2002) Using stable isotopes to estimate trophic position: models, methods, and assumptions. Ecology 83:703-718

R Development Core Team (2007) R: A Language and Environment for Statistical Computing. R Foundation for Statistical Computing, Vienna, Austria.

Salazar JG (2000) Damming the child of the ocean: the Three Gorges Project. J Environ Develop 9:160-1743

Sternberg R (2006) Damming the river: a changing perspective on altering nature. Renew Sust Energ Rev 10:165-197

Vander Zanden MJ (2001) Variation in $\delta^{13} \mathrm{C}$ and $\delta^{15} \mathrm{~N}$ trophic fractionation: implications for aquatic food web studies. Limnol Oceanogr 8:2061-2066

Wang J, Gu B, Huang J, Han X, Lin G et al (2014) Terrestrial contributions to the aquatic food web in the middle Yangtze River. PLoS One 7, e102473. doi:10. 1371/journal.pone.0102473

Wu J, Huang J, Han X et al (2003) Three-Gorges Dam-experiment in habitat fragmentation? Science 300:1239-1240

Xie P (2003) Three-Gorge Dam: risk to ancient fish. Science 302:1149

Xu X, Tan Y, Yang G (2013) Environmental impact assessments of the Three Gorges Project in China: issues and interventions. Earth-Sci Rev 124:115-125

Ye S, Li Z, Zhang T, Liu J, Xie S (2014) Assessing fish distribution and threats to fish biodiversity in the Yangtze River Basin, China. Ichthyol R 2:183-188

Yi YJ, Zhang SH (2012) Heavy metal (Cd, Cr, Cu, Hg, Pb, Zn) concentrations in seven fish species in relation to fish size and location along the Yangtze River. Environ Sci Pollut R 9:3989-3996

Zhang L, Xu J, Xie P, Zang X, Qiu G, Zeng J (2007) Stable isotope variations in particulate organic matter and a planktivorous fish in the Yangtze River. J Freshwater Ecol 3:383-386

Zhang G, Wu L, Li H, Liu M, Cheng F, Murphy BR, Xie S (2012) Preliminary evidence of delayed spawning and suppressed larval growth and condition of the major carps in the Yangtze River below the Three Gorges Dam. Environ Biol Fish 3:439-447

Zhang H, Wang CY, Yang DG, Du H, Wei QW, Kang M (2014) Spatial distribution and habitat choice of adult Chinese sturgeon (Acipenser sinensis Gray, 1835) downstream of Gezhouba Dam, Yangtze River, China. J Appl Ichthyol 6:1483-1491 